\title{
Myeloproliferative Diseases as Possible Risk Factor for Development of Chronic Thromboembolic Pulmonary Hypertension-A Genetic Study
}

\author{
Christina A. Eichstaedt ${ }^{1,2,3, *(0)}$, Jeremias Verweyen ${ }^{1,2}$, Michael Halank ${ }^{4}$, Nicola Benjamin ${ }^{1,2}$, \\ Christine Fischer ${ }^{3}$, Eckhard Mayer ${ }^{5}$, Stefan Guth ${ }^{5}$, Christoph B. Wiedenroth ${ }^{5}$, \\ Benjamin Egenlauf 1,2, Satenik Harutyunova ${ }^{1,2}$, Panagiota Xanthouli ${ }^{1,2}$, Alberto M. Marra ${ }^{1,2,6}$, \\ Heinrike Wilkens ${ }^{7}$, Ralf Ewert ${ }^{8}$, Katrin Hinderhofer ${ }^{3}$ and Ekkehard Grünig ${ }^{1,2}$ \\ 1 Centre for Pulmonary Hypertension, Thoraxklinik Heidelberg gGmbH, Heidelberg University Hospital, \\ Röntgenstr. 1, 69126 Heidelberg, Germany; Verweyen@stud.uni-heidelberg.de (J.V.); \\ Nicola.benjamin@med.uni-heidelberg.de (N.B.); Benjamin.Egenlauf@med.uni-heidelberg.de (B.E.); \\ Satenik.Harutyunova@med.uni-heidelberg.de (S.H.); Panagiota.Xanthouli@med.uniheidelberg.de (P.X.); \\ albertomaria.marra@unina.it (A.M.M.); Ekkehard.Gruenig@med.uni-heidelberg.de (E.G.) \\ 2 Translational Lung Research Centre (TLRC), German Centre for Lung Research (DZL), \\ Im Neuenheimer Feld 156, 69120 Heidelberg, Germany \\ 3 Laboratory of Molecular Genetic Diagnostics, Institute of Human Genetics, Heidelberg University, \\ Im Neuenheimer Feld 366, 69120 Heidelberg, Germany; Christine.Fischer@med.uni-heidelberg.de (C.F.); \\ Katrin.Hinderhofer@med.uni-heidelberg.de (K.H.) \\ 4 Department of Internal Medicine I, Carl Gustav Carus University Hospital, Technical University of Dresden, \\ Fetscherstraße 74,01307 Dresden, Germany; Michael.Halank@uniklinikum-dresden.de \\ 5 Kerckhoff Heart and Thorax Center, Department of Thoracic Surgery, Benekestr. 2-8, \\ 61231 Bad Nauheim, Germany; S.Guth@kerckhoff-klinik.de (S.G.); \\ c.wiedenroth@kerckhoff-klinik.de (C.B.W.); E.Mayer@kerckhoff-klinik.de (E.M.) \\ 6 IRCCS SDN Research Institute, Via F. Crispi 8, 80121 Naples, Italy \\ 7 Department of Internal Medicine V-Pneumology, Allergology and Critical Care Medicine, \\ University Hospital of Saarland, Kirrberger Str., 66424 Homburg, Saar, Germany; Heinrike.Wilkens@uks.eu \\ 8 Department of Internal Medicine B-Cardiology, Intensive Care, \\ Pulmonary Medicine and Infectious Diseases, University of Greifswald, Ferdinand-Sauerbruch-Str., \\ 17475 Greifswald, Germany; ewert@uni-greifswald.de \\ * Correspondence: christina.eichstaedt@med.uni-heidelberg.de; Tel.: +49-6221-396-1221; \\ Fax: +49-6221-396-1222
}

Received: 6 April 2020; Accepted: 6 May 2020; Published: 8 May 2020

Abstract: Chronic thromboembolic pulmonary hypertension (CTEPH) is a rare disease which is often caused by recurrent emboli. These are also frequently found in patients with myeloproliferative diseases. While myeloproliferative diseases can be caused by gene defects, the genetic predisposition to CTEPH is largely unexplored. Therefore, the objective of this study was to analyse these genes and further genes involved in pulmonary hypertension in CTEPH patients. A systematic screening was conducted for pathogenic variants using a gene panel based on next generation sequencing. CTEPH was diagnosed according to current guidelines. In this study, out of $40 \mathrm{CTEPH}$ patients $4(10 \%)$ carried pathogenic variants. One patient had a nonsense variant (c.2071A >T p.Lys691*) in the BMPR2 gene and three further patients carried the same pathogenic variant (missense variant, c.1849G > T p.Val617Phe) in the Janus kinase 2 (JAK2) gene. The latter led to a myeloproliferative disease in each patient. The prevalence of this JAK2 variant was significantly higher than expected $(p<0.0001)$. CTEPH patients may have a genetic predisposition more often than previously thought. The predisposition for myeloproliferative diseases could be an additional risk factor for CTEPH development. Thus, clinical screening for myeloproliferative diseases and genetic testing may be considered also for CTEPH patients. 
Keywords: pulmonary vascular resistance; chronic thromboembolic pulmonary hypertension; genetic predisposition; Janus kinase 2 (JAK2)

\section{Introduction}

Chronic thromboembolic pulmonary hypertension (CTEPH) is a rare form of pulmonary hypertension $(\mathrm{PH})$ and is characterised by organised thrombotic material and remodelled pulmonary vasculature as well as deficient angiogenesis, altered fibrinogen resolution and endothelial dysfunction [1,2]. Together these processes result in increased pulmonary vascular resistance leading to right heart failure [3]. Hypertrophy and muscularisation of the systemic bronchial vasculature and the formation of bronchial-pulmonary shunts directing the blood away from obstructed pulmonary vessels have also been described in humans and a porcine CTEPH model [4]. The exact interplay between factors in the pathogenesis still remains unclear but the process is frequently set in motion by acute or recurrent pulmonary embolism [5]. Around $4 \%$ of all patients who survive an acute pulmonary embolism will develop CTEPH [6]. While a number of risk factors for venous thromboembolism and CTEPH overlap such as non-O-blood group, phospholipid antibodies and elevated factor VIII [7], other risk factors only predispose to venous thromboembolism and not to CTEPH such as male sex and antithrombin deficiency $[7,8]$. Myeloproliferative disorders such as polycythaemia vera or essential thrombocythemia can also lead to thromboembolisms [9] and were identified together with CTEPH in more than ten patients so far [10-13]. In some of these patients, a pathogenic, somatic variant in the Janus kinase 2 (JAK2) gene has been detected [13] and in one case CTEPH and the myeloproliferative disease was diagnosed in the same patient at the same time [11]. Moreover, differential gene expression of more than 1600 genes was detected in pulmonary artery endothelial cells from CTEPH patients in comparison to healthy controls [14].

While pathogenic variants in the bone morphogenetic protein receptor 2 gene (BMPR2) and related pathway genes $[15,16]$ have been described in patients with pulmonary arterial hypertension (PAH) only two studies reported CTEPH patients with pathogenic variants in the BMPR2 gene [17,18]. In addition, pathogenic variants of further PAH genes such as ACVRL1, CAV1, KCNK3 and SMAD9 have been described in a single study screening 49 CTEPH patients [18]. In contrast, earlier studies could not identify any pathogenic variant in BMPR2 including a total of $124 \mathrm{CTEPH}$ patients [19-22]. In support of a genetic predisposition three descriptions of familial CTEPH exist albeit without identification of the exact genetic cause [23-25]. Thus, considering these reports of identified or suspected genetic predisposition the objective of this study was to systematically screen a CTEPH cohort for PAH and candidate genes predisposing to myeloproliferative disorders for pathogenic variants. This approach identified genetic predisposition for myeloproliferative disorders as a potential risk factor for CTEPH development.

\section{Results}

\subsection{Clinical Characterisation of Patient Cohort}

Forty CTEPH patients were diagnosed at an age of $61 \pm 13$ years, had a mean pulmonary artery pressure of $44 \pm 13 \mathrm{mmHg}$ with a pulmonary artery wedge pressure of $9 \pm 5 \mathrm{mmHg}$ and a pulmonary vascular resistance of $7.4 \pm 3.3$ Wood Units (WU) (Table 1). Most patients suffered from 1-2 acute lung embolisms prior to CTEPH diagnosis. Patients were examined for myeloproliferative diseases. Three patients $(7.5 \%)$ were additionally diagnosed with either polycythaemia vera, essential thrombocythemia, or primary myelofibrosis, respectively. Within the total cohort, $56 \%$ were treated by pulmonary endarterectomy (PEA), 10\% underwent balloon pulmonary angioplasty (BPA) sessions, $3 \%$ had both PEA and BPA and 31\% received no invasive intervention but only targeted PAH/CTEPH medication. 
Table 1. Clinical characteristics of chronic thromboembolic pulmonary hypertension (CTEPH) patients.

\begin{tabular}{|c|c|c|c|}
\hline \multirow{2}{*}{$\begin{array}{c}\text { Parameter } \\
\text { Age at diagnosis (years) }\end{array}$} & \multicolumn{2}{|c|}{ Mean \pm SD or $\%$} & \multirow{2}{*}{$\frac{\text { Cohort (n) * }}{40}$} \\
\hline & 61 & \pm 13 & \\
\hline Women $(\%)$ & 53 & & 40 \\
\hline 6-minute walking distance (m) & 425 & \pm 86 & 34 \\
\hline Previous history of pulmonary embolisms (\%) & 87 & & 39 \\
\hline Family history of thrombosis or pulmonary embolisms (\%) & 11 & & 36 \\
\hline Presence of myeloproliferative disease $(\%)$ & 7.5 & & 40 \\
\hline $\mathrm{N}$-terminal pro-brain natriuretic peptide (ng/l) & 1893 & \pm 4186 & 36 \\
\hline WHO functional class [26] & & & 36 \\
\hline WHO functional class II (\%) & 42 & & \\
\hline WHO functional class III (\%) & 58 & & \\
\hline Treatment & & & 39 \\
\hline Pulmonary endarterectomy (\%) & 33 & & \\
\hline Pulmonary endarterectomy + medication $(\%)$ & 23 & & \\
\hline Balloon pulmonary angioplasty + medication $(\%)$ & 10 & & \\
\hline $\begin{array}{l}\text { Pulmonary endarterectomy + balloon pulmonary angioplasty } \\
\qquad+ \text { medication }(\%)\end{array}$ & 3 & & \\
\hline Medication only $(\%)$ & 31 & & \\
\hline \multicolumn{4}{|l|}{ Haemodynamics } \\
\hline Mean pulmonary artery pressure $(\mathrm{mmHg})$ & 44 & \pm 13 & 36 \\
\hline Pulmonary artery wedge pressure $(\mathrm{mmHg})$ & 9 & \pm 5 & 34 \\
\hline Pulmonary vascular resistance (Wood Units) & 7.9 & \pm 3.6 & 35 \\
\hline Cardiac output (L/min) & 4.7 & \pm 1.1 & 28 \\
\hline Cardiac index $\left(\mathrm{L} / \mathrm{min} / \mathrm{m}^{2}\right)$ & 2.5 & \pm 0.5 & 27 \\
\hline
\end{tabular}

${ }^{*} \mathrm{n}$ varies for each parameter. Exact numbers are listed in this column; Abbreviations: SD: standard deviation, WHO: World Health Organization.

\subsection{Genetic Characterisation of Patients}

Out of 40 CTEPH patients $4(10 \%)$ carried pathogenic variants (class V), 8 further patients $(20 \%)$ carried variants of uncertain significance (VUS) in $3 \mathrm{PAH}$ and 7 candidate genes (Table 2) identified by next generation sequencing (NGS). One CTEPH patient had a germline nonsense variant (c.2071A>T p.Lys691*) in the bone morphogenetic protein rector 2 (BMPR2) gene. Three patients carried the same gain of function missense variant, c.1849G > T p.Val617Phe, in the Janus kinase 2 (JAK2) gene, which can give rise to acute and chronic myeloproliferative diseases (Table 2). The variant was most likely a somatic, thus not inherited but an acquired variant during the lifetime. So far the p.Val617Phe variant has only been identified as a somatic variant [27]. The variant was associated with polycythaemia vera in the first patient, with essential thrombocythemia in the second patient and with primary myelofibrosis in the third CTEPH patient. Two of the three patients with the JAK2 gain-of-function variant received a PEA while the other one was not operated due to co-morbidities. The two operated variant carriers subsequently received medical therapy as CTEPH was persisting and the co-morbid patient received a double combination therapy and long-term oxygen therapy. All variant carriers suffered from a pulmonary embolism prior to CTEPH development. Clinical characteristics of non-variant and variant carriers are given in Table 3. The prevalence of the JAK2 pathogenic variant in the general population was estimated to be $0.1 \%$ [28]. In our cohort 3 out of $40(7.5 \%)$ unselected CTEPH patients were carriers of the pathogenic variant significantly exceeding the expected percentage of $0-1$ carriers in our cohort $(p<0.0001)$. The $95 \%$ confidence interval for this variant was $1.6 \%-20.4 \%$. One further patient carried a VUS in JAK2 which has been described to have a weak gain of function effect on JAK2 activation in comparison to the wild type protein [29]. This variant is expected to be present in the germline, thus being inherited. The father of the variant carrier died due to a pulmonary embolism following an operation. 
Table 2. Genetic variants class III-V in CTEPH patients identified by next generation sequencing (NGS).

\begin{tabular}{|c|c|c|c|c|c|c|c|c|c|}
\hline Gene & RefSeq ID & Exon & c.DNA & Protein & n & Classification * & Prediction Programmes & CADD Score & gnom $A D(n)$ \\
\hline$B M P R 2$ & NM_001204 & 12 & c. $2071 \mathrm{~A}>\mathrm{T}$ & p. $($ Lys691*) & 1 & $\begin{array}{c}\text { Pathogenic } \\
\text { variant } \\
\text { (class V) }\end{array}$ & NA (nonsense) & 38.0 & 0 \\
\hline$J A K 2$ & NM_001322194 & 14 & c. $1849 \mathrm{G}>\mathrm{T}^{\#}$ & p.(Val617Phe) & 3 & $\begin{array}{c}\text { Pathogenic } \\
\text { variant } \\
\text { (class V) }\end{array}$ & gain-of-function & 31.0 & 97 \\
\hline$B M P R 1 B$ & NM_001203 & 8 & c. $556 \mathrm{~T}>\mathrm{A}$ & p.(Ser186Thr) & 1 & VUS (class III) & $3 / 4$ pathogenic & 23.6 & 3 \\
\hline BTNL2 & NM_001304561 & 4 & $\begin{array}{l}\text { c.710-4_710-8 } \\
\text { delinsCGCTC }\end{array}$ & intronic & 1 & VUS (class III) & NA (intronic) & NA & 0 \\
\hline IL6 & NM_000600 & 3 & c. $263 \mathrm{~A}>\mathrm{G}$ & p.(Asn88Ser) & 1 & VUS (class III) & 4/4 pathogenic & 22.4 & 3 \\
\hline$J A K 2$ & NM_001322194 & 24 & c. $3188 \mathrm{G}>\mathrm{A}$ & p.(Arg1063His) & 1 & VUS (Class III) & 2/4 pathogenic & 24.8 & 1272 \\
\hline KCNA5 & NM_002234 & 1 & c.213_245del & p.(Asp72_Pro82del) & 1 & VUS (Class III) & NA (in frame deletion) & NA & 147 \\
\hline NOTCH3 & NM_000435 & 1 & c.30_35dup & p.(Arg12ArgArgArg) & 1 & VUS (class III) & NA (in frame duplication) & NA & 0 \\
\hline SMAD4 & NM_005359 & 5 & c. $565 \mathrm{C}>\mathrm{T}$ & p.(Arg189Cys) & 1 & VUS (class III) & $3 / 4$ pathogenic & 23.6 & 99 \\
\hline SMAD6 & NM_005585 & 1 & c. $538 \mathrm{C}>\mathrm{G}$ & p.(Leu189Val) & 1 & VUS (class III) & $3 / 4$ pathogenic & 25.3 & 1 \\
\hline ТОРВР1 & NM_007027 & 14 & c. $2456 \mathrm{~A}>\mathrm{C}$ & p.(His819Pro) & 1 & VUS (class III) & $1 / 4$ pathogenic & 20.9 & 0 \\
\hline
\end{tabular}

\# Same somatic variant identified in three unrelated patients; * Variants were characterised following guidelines from the American College of Medical Genetics and Genomics [30]; Prediction programmes used: align Grantham variation Grantham deviation (Align-GVGD), sorting intolerant from tolerant (SIFT), PolyPhen2 and MutationTaster; Abbreviations: CADD: combined annotation dependent depletion, c.DNA: coding DNA, CTEPH: chronic thromboembolic pulmonary hypertension, gnomAD: genome aggregation database with 141.456 reported sequences, n: number of CTEPH patients with the variant, NA: not applicable, RefSeq ID: reference sequence identification number, VUS: variant of uncertain significance. 
Table 3. Clinical characteristics of non-variant and variant carriers.

\begin{tabular}{|c|c|c|c|c|c|c|c|}
\hline \multirow{2}{*}{$\begin{array}{c}\text { Parameter } \\
\text { Age at diagnosis (years) }\end{array}$} & \multicolumn{2}{|c|}{$\begin{array}{l}\text { Non-Variant Carriers * } \\
\text { Mean } \pm \text { SD or } \%\end{array}$} & \multirow{2}{*}{$\begin{array}{c}\text { BMPR2 Patient } \\
49\end{array}$} & \multirow{2}{*}{$\begin{array}{c}\text { JAK2 PV Patient } \\
81\end{array}$} & \multirow{2}{*}{$\frac{J A K 2 \text { ET Patient }}{65}$} & \multirow{3}{*}{$\begin{array}{c}\text { JAK2 MF Patient } \\
66 \\
\text { female }\end{array}$} & \multirow{2}{*}{$\begin{array}{c}\text { JAK2 VUS Patient } \\
51\end{array}$} \\
\hline & 57 & \pm 12 & & & & & \\
\hline Male:Female & $0.8: 1$ & & male & male & male & & female \\
\hline 6-minute walking distance $(\mathrm{m})$ & 432 & \pm 91 & 360 & NA ** & 411 & 429 & 414 \\
\hline Previous history of pulmonary embolisms (\%) & 85 & & yes & yes & Yes & yes & yes \\
\hline Family history of thrombosis / pulmonary embolisms (\%) & 8 & & absent & absent & absent & absent & PE \\
\hline Presence of myeloproliferative disease $(\%)$ & 0 & & absent & yes & yes & yes & absent \\
\hline N-terminal pro-brain natriuretic peptide $(\mathrm{ng} / \mathrm{l})$ & 1566 & \pm 4045 & 1386 & $12.630^{* * *}$ & 2975 & 2533 & 104 \\
\hline WHO functional class [26] II:III & $0.9: 1$ & & III & III & II & II & III \\
\hline PEA $(\%)$ & 38 & & & & & & \\
\hline PEA + medication $(\%)$ & 18 & & & & & & \\
\hline $\mathrm{BPA}+$ medication $(\%)$ & 12 & & riociguat & $\begin{array}{l}\text { riociguat, } \\
\text { macitentan. LTOT }\end{array}$ & PEA; riociguat, & PEA; riociguat & PEA; riociguat \\
\hline PEA + BPA + medication (\%) & 3 & & & & & & \\
\hline Medication only (\%) & 29 & & & & & & \\
\hline Mean pulmonary artery pressure $(\mathrm{mmHg})$ & 45 & \pm 14 & 51 & 45 & 35 & 32 & 41 \\
\hline Pulmonary artery wedge pressure $(\mathrm{mmHg})$ & 9 & \pm 5 & 2 & 8 & 6 & 12 & 10 \\
\hline Pulmonary vascular resistance (Wood Units) & 7.7 & \pm 3.6 & 10.2 & 8.6 & 4.6 & 4.4 & 6.2 \\
\hline Cardiac output $(\mathrm{L} / \mathrm{min})$ & 4.7 & \pm 1.2 & 4.8 & NA & 5.0 & 4.5 & 5.0 \\
\hline Cardiac index $\left(\mathrm{L} / \mathrm{min} / \mathrm{m}^{2}\right)$ & 2.5 & \pm 0.6 & 2.2 & 2.3 & 2.9 & 2.5 & 2.6 \\
\hline
\end{tabular}

${ }^{*} \mathrm{n}$ varies for each parameter; ${ }^{* *}$ Patient suffered from arthrosis and had difficulty walking; In addition, the same patient had a chronic renal insufficiency; Abbreviations: BMPR2:

bone morphogenetic protein receptor, BPA: balloon pulmonary angioplasty, ET: essential thrombocythemia, JAK2: Janus kinase 2, LTOT: long-term oxygen therapy, MF: myelofibrosis,

NA: not available, PE: pulmonary embolism, PEA: pulmonary endarterectomy, PV: polycythaemia vera, SD: standard deviation, VUS: variant of uncertain significance, WHO: World

Health Organization. 
Sanger sequencing revealed three other patients with either the thrombophilia predisposing regulatory prothrombin gene $\mathrm{F} 2$ variant c.20210G $>\mathrm{A}$, the known loss-of-function variant in the factor V-Leiden gene F5 c.1691G>A p.Arg506Glu or both variants together in a heterozygous state. No increased number of thrombosis events or pulmonary embolisms were reported for these three CTEPH patients. The variants were present in $5 \%$ of our cohort $(n=2$ each). No statistically significant enrichment of these gene variants in our cohort in comparison to the database genome aggregation database (gnomAD) could be identified ( $F 2: p=0.15, F 5: p=0.70$ ).

The family history of three patients revealed a pulmonary embolism in a first degree relative and a deep vein thrombosis in a relative of an additional patient. None of the corresponding index patients were carriers of a pathogenic variant (class V). However, one subject with pulmonary embolism was the relative of the variant carrier with the mildly activating JAK2 variant of uncertain significance.

\subsection{Clinical Characterisation of CTEPH Patient With BMPR2 Nonsense Variant}

Within the cohort one patient was identified with a germline BMPR2 nonsense variant (class V) leading to a premature stop codon (Table 2). The patient was diagnosed with inoperable CTEPH at 49 years of age (Table 3). Right heart catheterisation revealed a strongly elevated mean pulmonary artery pressure of $51 \mathrm{mmHg}$, pulmonary arterial wedge pressure of $2 \mathrm{mmHg}$, cardiac output of $4.8 \mathrm{l} / \mathrm{min}$, cardiac index of $2.2 \mathrm{l} / \mathrm{min} / \mathrm{m}^{2}$ and an elevated pulmonary vascular resistance of $10.2 \mathrm{WU}$. Scintigraphy showed incomplete reperfusion after lung embolisms on both sides. The diagnosis of inoperable CTEPH was confirmed by an international panel of experts and the patient was included into the CHEST study [31]. Since then the patient has been treated with riociguat and improved within six months of treatment from World Health Organization (WHO) functional class III to class II, increased 6-minute walking distance by $70 \mathrm{~m}$ to $470 \mathrm{~m}$ while reducing the Borg scale from 4 to 3 . In the same time frame the N-terminal pro-brain natriuretic peptide level fell from $1386 \mathrm{ng} / \mathrm{l}$ to $203 \mathrm{ng} / \mathrm{l}$. Echocardiography revealed an improvement of systolic pulmonary arterial pressure by $5 \mathrm{mmHg}$, of the tricuspid annular plane systolic excursion by $2 \mathrm{~mm}$ and a reduction of the right arterial area by $3 \mathrm{~cm}^{2}$. The next right heart catheterisation after 2.5 years showed a drastic improvement with halved pulmonary vascular resistance and a $40 \%$ increase of cardiac index. The latest right heart catheterisation confirmed these haemodynamic improvements particularly concerning pulmonary vascular resistance $(5.50 \mathrm{WU})$, cardiac output $(6.9 \mathrm{l} / \mathrm{min})$ and cardiac index $\left(3.1 \mathrm{l} / \mathrm{min} / \mathrm{m}^{2}\right)$. The mean pulmonary artery pressure remained stable at $50 \mathrm{mmHg}$ and pulmonary arterial wedge pressure rose to $14 \mathrm{mmHg}$.

\section{Discussion}

To the best of our knowledge, this is the first systematic genetic assessment in CTEPH patients using a panel based on NGS including all currently known PAH genes and further genes predisposing to myeloproliferative diseases. We could identify pathogenic variants in the BMPR2 and JAK2 gene, respectively, in $10 \%$ of the patients. This is the third study to report a pathogenic variant in BMPR2 in a CTEPH patient, which is usually observed in heritable PAH patients, pointing towards a possible overlap in genetic predisposition of these two precapillary forms of PH. Moreover, this study highlights the co-occurrence of a gain-of-function variant known from polycythaemia vera, essential thrombocythemia and primary myelofibrosis in three CTEPH patients as a possible co-factor for CTEPH development. The frequency of the JAK2 variant in our cohort was highly significantly increased compared to its normal distribution in the general population. Thus, gene panel diagnostics could also be clinically and pathophysiologically relevant for the work-up of CTEPH patients.

\subsection{Pathogenic Variants for Thrombophilia in CTEPH}

Rare pathogenic variants and common polymorphisms may contribute to an increased risk of thrombus formation or non-resolution and subsequent development of CTEPH [32,33]. The JAK2 pathogenic variant p.Val617Phe identified in this study was most likely a somatic variant originating 
from genetic changes which occurred in haematopoietic progenitor cells. It may act as a risk factor for CTEPH development as it can lead to increased proliferation of myeloid cells, resulting in somatic diseases such as acute myeloid leukaemia, Budd-Chiari syndrome, or the myeloproliferative diseases primary myelofibrosis, essential thrombocythemia and polycythaemia vera. In this study it was associated with polycythaemia vera, primary myelofibrosis and essential thrombocythemia in three CTEPH patients. As a somatic variant, the predisposition to myeloproliferative disorders could not be passed on to any children as we expect germline cells not to have been affected. The pathogenic variant was previously identified in one CTEPH patient with essential thrombocythemia [13] and one CTEPH patient with primary myelofibrosis [34]. Moreover, nine further CTEPH patients were reported to have polycythaemia vera albeit without genetic testing for the predisposing JAK2 pathogenic variant [10-12]. However, since this pathogenic variant is present in over $95 \%$ of polycythaemia vera patients [35] there is a high probability that these patients also carried the pathogenic variant. This supports the notion that myeloproliferative diseases may be more prevalent among CTEPH patients than previously reported. In one study $1.2 \%$ of $433 \mathrm{CTEPH}$ patients presented with primary myelofibrosis [36]. However, neither sequencing data nor other non-malignant myeloproliferative neoplasms were investigated in this patient cohort. Thus, further myeloproliferative diseases might have been missed and thus the prevalence of these diseases in this cohort could have been underestimated. Nevertheless, myeloproliferative disorders were taken-up as risk factors for CTEPH development in the European Society of Cardiology / European Respiratory Society guidelines from 2009 [37] but were dropped again in the latest guidelines from 2016 [38]. However, our study supports an association with CTEPH development and a possible status as an additional risk factor.

The pathogenic variant in the $J A K 2$ gene c.1849G $>\mathrm{T}$ p.Val617Phe led to an exchange of the conserved amino acid valine by phenylalanine resulting in a loss of function within the gene's self-inhibitory domain. Subsequently, the JAK2 gene was constantly activated and initiated the downstream signal transducers and activators of transcription pathway [35]. Hence, this pathogenic variant resulted in a gain of function of the protein leading to myeloproliferative diseases. It is important to note that probably not the JAK2 pathogenic variant itself has a causal effect on CTEPH manifestation, but its effects on increased erythrocytosis and increased risk of thrombosis may increase the likelihood of CTEPH development. Adir and colleagues even suggested CTEPH itself could be a first manifestation of the myeloproliferative disease [39]. Alternatively, both diseases may occur independently from each other in the same patient.

\subsection{Pathogenic Variants in the BMPR2 and Other PAH Genes in CTEPH}

There may be some overlap between CTEPH and PAH pathophysiology concerning in situ thrombosis, even though caused by different mechanisms [40], and microvascular remodelling up to the formation of (plexiform) lesions in CTEPH patients [1]. Equally, PAH patients can also present with thrombotic lesions, in particular in smaller vessels [41]. Thus, a misclassification of CTEPH and PAH may be possible. The patient described in this study carrying a pathogenic variant in BMPR2 was included in the CHEST study [31] and therefore diagnosed to suffer from CTEPH by an international expert panel. The identified pathogenic variant was not only relevant for the patient but also for the patient's children as it could have been passed on to the next generation. The results of our study confirm a case report of a CTEPH patient with a pathogenic variant in BMPR2 [17] and a larger study with 49 CTEPH patients which identified BMPR2 pathogenic variants in about $10 \%$ of patients $[17,18]$. Our study and these two previous publications $[17,18]$ support the hypothesis that genetic diagnostic testing for PAH genes and myeloproliferative disorder associated genes could assist in the clinical characterisation of CTEPH patients. 


\section{Materials and Methods}

\subsection{Study Subject Characterisation}

According to current guidelines [38] all patients underwent a detailed clinical work-up to establish the diagnosis of CTEPH. Since PAH can be a differential diagnosis of CTEPH, only patients with definite diagnosis have been included in the study. The assessment included right heart catheterisation, ventilation / perfusion lung scan, computed tomography angiography and pulmonary angiography. Moreover, patients received assessments of medical history, family history, physical examination, electrocardiogram, lung function test, chest x-ray, echocardiography, WHO functional class assessment [26] and laboratory parameters. Patients were treated at expert centres for pulmonary hypertension in Heidelberg and in Dresden, Germany. Operability of the patients was determined by German expert centres for pulmonary endarterectomy ( Bad Nauheim or Homburg). Further diseases which could have contributed to CTEPH were evaluated. For the diagnosis of a myeloproliferative disease laboratory parameters were measured and the gene Janus Kinase 2 (JAK2) analysed for the predisposing gain-of-function variant c.1849G > T p.Val617Phe with NGS. Thrombophilia work-up included Sanger sequencing of the predisposing regulatory prothrombin gene F2 variant c.20210G $>$ A (rs1799963, also termed c. ${ }^{* 97 G>A}$ in current reference sequence NM_000506.5) and the known loss-of-function variant in the factor V-Leiden gene F5 c.1691G>A p.Arg506Glu (rs6025, also termed c.1601G>A p.Arg534Glu in current reference sequence NM_000130.5). All subjects gave their informed consent for inclusion before they participated in the study. Patients were enrolled between the years 2016 and 2019. The inclusion in the study was on average 4 \pm 3 years after initial diagnosis. This study was conducted in accordance with the current version of the Declaration of Helsinki. The Ethics Committee at Heidelberg University had no objections against this study (project identification codes 065/2001, approval date: 08 August 2001 and S-426/2017, approval date: 17 October 2017).

\subsection{DNA Analysis}

DNA was extracted from peripheral blood of CTEPH patients (Autogene, Qiagen, Hilden, Germany) using standardised procedures. Sequence variants in patients were detected using a gene panel including PAH and genes predisposing for myeloproliferative diseases (ACVRL1, BMPR1B, BMPR2, CAV1, EIF2AK4, ENG, GDF2, JAK2, KCNA5, KCNK3, KLF2, SMAD4, SMAD9 and TBX4) and further candidate genes (ACVR1, BMP2, BMPR1A, BTNL2, CREB1, CYP1B1, EPAS1, FOXO1, HGR, ID1, ID2, ID3, ID4, IL6, KLF4, KLF5, NOTCH3, SMAD1, SMAD5, SMAD6, SMAD7, SOD2, TBX2, TMEM70, TOPBP1, VCAN, VHL and ZFYVE16) based on NGS, as described previously [16]. In contrast to the previous publication, additional genes were included and the sample preparation and sequencing was based on SureSelect QXT (Agilent Technologies, Santa Clara, CA, USA).

Variants in exonic regions and exon-intron boundaries were characterised following recommendations of the Human Genome Variation Society (version 2.15.11) and the genetic variant interpretation tool of the American College of Medical Genetics [30]. Non-synonymous missense variants with a population frequency of $<1 \%$ were assessed using four in silico prediction programmes (MutationTaster, sorting intolerant from tolerant (SIFT), align Grantham variation Grantham deviation (Align-GVGD), PolyPhen2); the impact on splice sites were evaluated utilising the prediction programmes SpliceSiteFinder-like, MaxEntScan, splice site prediction by neural networks (NNSPLICE), GeneSplicer and Human Splicing Finder (Alamut Visual 2.11, interactive biosoftware, Rouen, France). The combined annotation dependent depletion (CADD) score was calculated to consider further algorithms [42] and to exclude variants with a score $<20$. Benign variants and likely benign variants (class I and II) were considered polymorphisms and not followed-up.

\subsection{Statistics}

Variants of uncertain significance (VUS, class III) and (likely) pathogenic variants (class IV and $\mathrm{V}$ ) in PAH genes were compared to their frequency in a presumably healthy control population, 
i.e., individuals listed in gnomAD [43]. Clinical parameters of CTEPH patients were given in \% for frequency distributions or as mean \pm standard deviation. Overrepresentation of the F2, F5 and JAK2 variant in our cohort was investigated with the Fisher's exact test implemented in BiAS version 11.4 (epsilon-Verlag GbR Hochheim, Darmstadt, Germany). A $p$-value $<0.05$ was considered statistically significant. Frequency distributions of the F2, F5 and JAK2 variant were provided with respective $95 \%$ confidence intervals.

\title{
5. Conclusions
}

The predisposition for myeloproliferative diseases could be a further risk factor for CTEPH development and may therefore add to the work-up of CTEPH patients. In rare cases also a genetic predisposition in PAH genes could be identified providing relevant information for the treatment regimen and also family members. Thus, genetic diagnostics may be considered also for CTEPH patients to investigate a hereditary component for pulmonary hypertension and myeloproliferative disorders.

Author Contributions: E.G.: K.H., C.A.E., J.V., R.E. contributed substantially to the study conception and design. C.B.W., A.M.M., E.G., B.E., S.H., S.G., E.M., H.W., P.X., M.H., J.V. performed the assessments and patient examinations. M.H., J.V., C.A.E. performed the data collection. N.B., C.F., C.A.E., J.V. performed the data analysis. All authors contributed to data interpretation and to the writing of the manuscript. All authors have read and approved the manuscript and agree to be accountable for all aspects of the work in ensuring that questions related to the accuracy or integrity of any part of the work are appropriately investigated, resolved, and documented in the literature.

Funding: Funding to pay publication charges for this article was provided by the Centre for Pulmonary Hypertension, Thoraxklinik at Heidelberg University Hospital.

Conflicts of Interest: C.A.E. nothing to disclose. J.V. nothing to disclose; M.H. received advisory board member, speaker honoraria and travel support from Acceleron, Actelion, AstraZeneca, Bayer AG, BerlinChemie, GSK, Janssen-Cilag, OMT, MSD and Novartis, outside the submitted work; N.B. received speaker honoraria and travel support from Actelion and Bayer, outside the submitted work; C.F. nothing to disclose; E.M. reports nonfinancial support from the German Center for Lung Research, during the conduct of the study; personal fees from Actelion Pharmaceuticals, Bayer, Pfizer, GSK and MSD, outside the submitted work; S.G. reports nonfinancial support from the German Center for Lung Research, during the conduct of the study; personal fees from Actelion Pharmaceuticals, Bayer, Pfizer and GSK, outside the submitted work; C.B.W. reports nonfinancial support from the German Center for Lung Research and the Collaborative Research Center (CRC) 1213, central project 01 (CP01), during the conduct of the study; personal fees from Actelion Pharmaceuticals, AOP Orphan Pharmaceuticals AG, Bayer AG, BTG, MSD, and Pfizer, outside the submitted work; B.E. received honoraria for lectures and travel fees from Janssen Cilag (Actelion), MSD, Bayer and OMT, outside the submitted work; S.H. received travel support from Actelion and OMT, outside the submitted work; P.X. nothing to disclose; A.M.M. nothing to disclose; H.W. received fess for consultations and/or lectures from Actelion/Janssen, Bayer/MSD, Boehringer Ingelheim, GSK, Novartis, Pfizer and Roche, outside the submitted work; R.E. received advisory board member and speaker honoraria from Actelion, United Therapeutics, Boehringer Ingelheim, AstraZeneca, Novartis and Pfizer; speaker honoraria from OMT and research grants from Actelion, Boehringer Ingelheim and OMT, outside of the submitted work; KH nothing to disclose; E.G. received advisory board member and speaker honoraria from Actelion, Bayer/MSD, GSK, United Therapeutics, Novartis, Pfizer, OrphaSwiss GmbH outside the submitted work. The funders had no role in the design of the study; in the collection, analyses, or interpretation of data; in the writing of the manuscript, or in the decision to publish the results.

\author{
Abbreviations \\ BMPR2 Bone morphogenetic protein receptor 2 \\ BPA Balloon pulmonary angioplasty \\ CADD Combined annotation dependent depletion \\ CTEPH Chronic thromboembolic pulmonary hypertension \\ DOAJ Directory of open access journals \\ gnomAD Genome aggregation database \\ JAK2 Janus kinase 2 \\ MDPI Multidisciplinary Digital Publishing Institute \\ NGS Next generation sequencing
}


PAH Pulmonary arterial hypertension

PEA Pulmonary endarterectomy

$\mathrm{PH} \quad$ Pulmonary hypertension

VUS Variant of uncertain significance

WHO World Health Organization

WU Wood units

\section{References}

1. Lang, I.M.; Dorfmüller, P.; Vonk Noordegraaf, A. The Pathobiology of Chronic Thromboembolic Pulmonary Hypertension. Ann. Am. Thorac. Soc. 2016, 13 (Suppl. 3), S215-S221. [CrossRef] [PubMed]

2. Kim, N.H.; Delcroix, M.; Jais, X.; Madani, M.M.; Matsubara, H.; Mayer, E.; Ogo, T.; Tapson, V.F.; Ghofrani, H.A.; Jenkins, D.P. Chronic thromboembolic pulmonary hypertension. Eur. Respir. J. 2019, 53, 1801915. [CrossRef]

3. Taniguchi, Y.; Jais, X.; Jevnikar, M.; Boucly, A.; Weatherald, J.; Brenot, P.; Planche, O.; Parent, F.; Savale, L.; Fadel, E.; et al. Predictors of survival in patients with not-operated chronic thromboembolic pulmonary hypertension. J. Heart Lung Transpl. 2019, 38, 833-842. [CrossRef] [PubMed]

4. Dorfmüller, P.; Gunther, S.; Ghigna, M.R.; Thomas de Montpreville, V.; Boulate, D.; Paul, J.F.; Jais, X.; Decante, B.; Simonneau, G.; Dartevelle, P.; et al. Microvascular disease in chronic thromboembolic pulmonary hypertension: A role for pulmonary veins and systemic vasculature. Eur. Respir. J. 2014, 44, 1275-1288. [CrossRef] [PubMed]

5. Simonneau, G.; Torbicki, A.; Dorfmüller, P.; Kim, N. The pathophysiology of chronic thromboembolic pulmonary hypertension. Eur. Respir. Rev. 2017, 26, 160112. [CrossRef] [PubMed]

6. Delcroix, M.; Kerr, K.; Fedullo, P. Chronic Thromboembolic Pulmonary Hypertension. Epidemiology and Risk Factors. Ann. Am. Thorac. Soc. 2016, 13 (Suppl. 3), S201-S206. [CrossRef]

7. Lang, I.M.; Pesavento, R.; Bonderman, D.; Yuan, J.X. Risk factors and basic mechanisms of chronic thromboembolic pulmonary hypertension: A current understanding. Eur. Respir. J. 2013, 41, 462-468. [CrossRef]

8. Kramm, T.; Wilkens, H.; Fuge, J.; Schafers, H.J.; Guth, S.; Wiedenroth, C.B.; Weingard, B.; Huscher, D.; Pittrow, D.; Cebotari, S.; et al. Incidence and characteristics of chronic thromboembolic pulmonary hypertension in Germany. Clin. Res. Cardiol. 2018, 107, 548-553. [CrossRef]

9. Landolfi, R.; Di Gennaro, L.; Falanga, A. Thrombosis in myeloproliferative disorders: Pathogenetic facts and speculation. Leukemia 2008, 22, 2020-2028. [CrossRef]

10. Blauwet, L.A.; Edwards, W.D.; Tazelaar, H.D.; McGregor, C.G. Surgical pathology of pulmonary thromboendarterectomy: A study of 54 cases from 1990 to 2001. Hum. Pathol. 2003, 34, 1290-1298. [CrossRef]

11. Guilpain, P.; Montani, D.; Damaj, G.; Achouh, L.; Lefrere, F.; Le Pavec, J.; Marfaing-Koka, A.; Dartevelle, P.; Simonneau, G.; Humbert, M.; et al. Pulmonary hypertension associated with myeloproliferative disorders: A retrospective study of ten cases. Respiration 2008, 76, 295-302. [CrossRef] [PubMed]

12. Nand, S.; Orfei, E. Pulmonary hypertension in polycythemia vera. Am. J. Hematol. 1994, 47, $242-244$. [CrossRef] [PubMed]

13. Magge, A.; Kaiser, T.; Mutneja, R.; Grover, P.; Farmington, C. Chronic Thromboembolic Pulmonary Hypertension in the Setting of Essential Thrombocytosis. Chest 2016, 150, 1226A. [CrossRef]

14. Gu, S.; Su, P.; Yan, J.; Zhang, X.; An, X.; Gao, J.; Xin, R.; Liu, Y. Comparison of gene expression profiles and related pathways in chronic thromboembolic pulmonary hypertension. Int. J. Mol. Med. 2014, 33, 277-300. [CrossRef]

15. Machado, R.D.; Southgate, L.; Eichstaedt, C.A.; Aldred, M.A.; Austin, E.D.; Best, D.H.; Chung, W.K.; Benjamin, N.; Elliott, C.G.; Eyries, M.; et al. Pulmonary arterial hypertension: A current perspective on established and emerging molecular genetic defects. Hum. Mutat. 2015, 36, 1113-1127. [CrossRef] [PubMed]

16. Song, J.; Eichstaedt, C.A.; Rodríguez Viales, R.; Benjamin, N.; Harutyunova, S.; Fischer, C.; Grünig, E.; Hinderhofer, K. Identification of genetic defects in pulmonary arterial hypertension by a new gene panel diagnostic tool. Clin. Sci. 2016, 130, 2043-2052. [CrossRef] [PubMed]

17. Feng, Y.X.; Liu, D.; Sun, M.L.; Jiang, X.; Sun, N.; Mao, Y.M.; Jing, Z.C. BMPR2 germline mutation in chronic thromboembolic pulmonary hypertension. Lung 2014, 192, 625-627. [CrossRef] 
18. Xi, Q.; Liu, Z.; Zhao, Z.; Luo, Q.; Huang, Z. High Frequency of Pulmonary Hypertension-Causing Gene Mutation in Chinese Patients with Chronic Thromboembolic Pulmonary Hypertension. PLoS ONE 2016, 11, e0147396. [CrossRef]

19. Kataoka, M.; Aimi, Y.; Yanagisawa, R.; Ono, M.; Oka, A.; Fukuda, K.; Yoshino, H.; Satoh, T.; Gamou, S. Alu-mediated nonallelic homologous and nonhomologous recombination in the BMPR2 gene in heritable pulmonary arterial hypertension. Genet. Med. 2013, 15, 941-947. [CrossRef]

20. Ulrich, S.; Szamalek-Hoegel, J.; Hersberger, M.; Fischler, M.; Garcia, J.S.; Huber, L.C.; Grünig, E.; Janssen, B.; Speich, R. Sequence variants in BMPR2 and genes involved in the serotonin and nitric oxide pathways in idiopathic pulmonary arterial hypertension and chronic thromboembolic pulmonary hypertension: Relation to clinical parameters and comparison with left heart disease. Respiration 2010, 79, 279-287. [CrossRef]

21. Suntharalingam, J.; Machado, R.D.; Sharples, L.D.; Toshner, M.R.; Sheares, K.K.; Hughes, R.J.; Jenkins, D.P.; Trembath, R.C.; Morrell, N.W.; Pepke-Zaba, J. Demographic features, BMPR2 status and outcomes in distal chronic thromboembolic pulmonary hypertension. Thorax 2007, 62, 617-622. [CrossRef] [PubMed]

22. Opitz, I.; Kirschner, M.B. Molecular Research in Chronic Thromboembolic Pulmonary Hypertension. Int. J. Mol. Sci. 2019, 20, 784. [CrossRef] [PubMed]

23. Desmarais, J.; Elliott, C.G. Familial Chronic Thromboembolic Pulmonary Hypertension. Chest 2016, 149, e99-e101. [CrossRef] [PubMed]

24. Kataoka, M.; Momose, Y.; Aimi, Y.; Fukuda, K.; Gamou, S.; Satoh, T. Familial Chronic Thromboembolic Pulmonary Hypertension in a Pair of Japanese Brothers. Chest 2016, 150, 748-749. [CrossRef]

25. Roik, M.; Wretowski, D.; Irzyk, K.; Labyk, A.; Dzikowska-Diduch, O.; Pruszczyk, P. Familial chronic thromboembolic pulmonary hypertension in a mother and a son: Successful treatment with refined balloon pulmonary angioplasty. Pol. Arch. Med. Wewn. 2016, 126, 1014-1016. [CrossRef]

26. Barst, R.J.; McGoon, M.; Torbicki, A.; Sitbon, O.; Krowka, M.J.; Olschewski, H.; Gaine, S. Diagnosis and differential assessment of pulmonary arterial hypertension. J. Am. Coll. Cardiol. 2004, 43, 40S-47S. [CrossRef]

27. Sirota, L.L.; Gerstein, H. Familial essential thrombocythemia associated with JAK2 V617F mutation in siblings. J. Comm. Oncol. 2017, 1, e274-e276.

28. Nielsen, C.; Bojesen, S.E.; Nordestgaard, B.G.; Kofoed, K.F.; Birgens, H.S. JAK2V617F somatic mutation in the general population: Myeloproliferative neoplasm development and progression rate. Haematologica 2014, 99, 1448-1455. [CrossRef]

29. Kapralova, K.; Horvathova, M.; Pecquet, C.; Fialova Kucerova, J.; Pospisilova, D.; Leroy, E.; Kralova, B.; Milosevic Feenstra, J.D.; Schischlik, F.; Kralovics, R.; et al. Cooperation of germ line JAK2 mutations E846D and $\mathrm{R} 1063 \mathrm{H}$ in hereditary erythrocytosis with megakaryocytic atypia. Blood 2016, 128, 1418-1423. [CrossRef]

30. Richards, S.; Aziz, N.; Bale, S.; Bick, D.; Das, S.; Gastier-Foster, J.; Grody, W.W.; Hegde, M.; Lyon, E.; Spector, E.; et al. Standards and guidelines for the interpretation of sequence variants: A joint consensus recommendation of the American College of Medical Genetics and Genomics and the Association for Molecular Pathology. Genet. Med. 2015, 17, 405-424. [CrossRef]

31. Ghofrani, H.A.; D'Armini, A.M.; Grimminger, F.; Hoeper, M.M.; Jansa, P.; Kim, N.H.; Mayer, E.; Simonneau, G.; Wilkins, M.R.; Fritsch, A.; et al. Riociguat for the treatment of chronic thromboembolic pulmonary hypertension. N. Engl. J. Med. 2013, 369, 319-329. [CrossRef] [PubMed]

32. Morris, T.A.; Marsh, J.J.; Chiles, P.G.; Magana, M.M.; Liang, N.C.; Soler, X.; Desantis, D.J.; Ngo, D.; Woods, V.L., Jr. High prevalence of dysfibrinogenemia among patients with chronic thromboembolic pulmonary hypertension. Blood 2009, 114, 1929-1936. [CrossRef] [PubMed]

33. Suntharalingam, J.; Goldsmith, K.; van Marion, V.; Long, L.; Treacy, C.M.; Dudbridge, F.; Toshner, M.R.; Pepke-Zaba, J.; Eikenboom, J.C.; Morrell, N.W. Fibrinogen Aalpha Thr312Ala polymorphism is associated with chronic thromboembolic pulmonary hypertension. Eur. Respir. J. 2008, 31, 736-741. [CrossRef]

34. Brabrand, M.; Hansen, K.N.; Laursen, C.B.; Larsen, T.S.; Vestergaard, H.; Abildgaard, N. Frequency and etiology of pulmonary hypertension in patients with myeloproliferative neoplasms. Eur. J. Haematol. 2019, 102, 227-234. [CrossRef] [PubMed]

35. O'Sullivan, J.; Mead, A.J. Heterogeneity in myeloproliferative neoplasms: Causes and consequences. Adv. Biol. Regul. 2019, 71, 55-68. [CrossRef] [PubMed] 
36. Bonderman, D.; Wilkens, H.; Wakounig, S.; Schafers, H.J.; Jansa, P.; Lindner, J.; Simkova, I.; Martischnig, A.M.; Dudczak, J.; Sadushi, R.; et al. Risk factors for chronic thromboembolic pulmonary hypertension. Eur. Respir. J. 2009, 33, 325-331. [CrossRef] [PubMed]

37. Galiè, N.; Hoeper, M.M.; Humbert, M.; Torbicki, A.; Vachiery, J.L.; Barbera, J.A.; Beghetti, M.; Corris, P.; Gaine, S.; Gibbs, J.S.; et al. Guidelines for the diagnosis and treatment of pulmonary hypertension: The Task Force for the Diagnosis and Treatment of Pulmonary Hypertension of the European Society of Cardiology (ESC) and the European Respiratory Society (ERS), endorsed by the International Society of Heart and Lung Transplantation (ISHLT). Eur. Heart J. 2009, 30, 2493-2537.

38. Galiè, N.; Humbert, M.; Vachiery, J.L.; Gibbs, S.; Lang, I.; Torbicki, A.; Simonneau, G.; Peacock, A.; Vonk Noordegraaf, A.; Beghetti, M.; et al. 2015 ESC/ERS Guidelines for the diagnosis and treatment of pulmonary hypertension: The Joint Task Force for the Diagnosis and Treatment of Pulmonary Hypertension of the European Society of Cardiology (ESC) and the European Respiratory Society (ERS): Endorsed by: Association for European Paediatric and Congenital Cardiology (AEPC), International Society for Heart and Lung Transplantation (ISHLT). Eur. Heart J. 2016, 37, 67-119.

39. Adir, Y.; Elia, D.; Harari, S. Pulmonary hypertension in patients with chronic myeloproliferative disorders. Eur. Respir. Rev. 2015, 24, 400-410. [CrossRef]

40. Olschewski, H.; Rich, S. Are anticoagulants still indicated in pulmonary arterial hypertension? Pulm. Circ. 2018, 8, 2045894018807681. [CrossRef]

41. Yi, E.S.; Kim, H.; Ahn, H.; Strother, J.; Morris, T.; Masliah, E.; Hansen, L.A.; Park, K.; Friedman, P.J. Distribution of obstructive intimal lesions and their cellular phenotypes in chronic pulmonary hypertension. A morphometric and immunohistochemical study. Am. J. Respir. Crit. Care Med. 2000, 162, 1577-1586. [CrossRef] [PubMed]

42. Kircher, M.; Witten, D.M.; Jain, P.; O’Roak, B.J.; Cooper, G.M.; Shendure, J. A general framework for estimating the relative pathogenicity of human genetic variants. Nat. Genet. 2014, 46, 310-315. [CrossRef] [PubMed]

43. Lek, M.; Karczewski, K.J.; Minikel, E.V.; Samocha, K.E.; Banks, E.; Fennell, T.; O’Donnell-Luria, A.H.; Ware, J.S.; Hill, A.J.; Cummings, B.B.; et al. Analysis of protein-coding genetic variation in 60,706 humans. Nature 2016, 536, 285-291. [CrossRef] [PubMed]

(C) 2020 by the authors. Licensee MDPI, Basel, Switzerland. This article is an open access article distributed under the terms and conditions of the Creative Commons Attribution (CC BY) license (http://creativecommons.org/licenses/by/4.0/). 